\title{
Beyond the skin-bag
}

\section{The brain extends its reach outside the body, so are we all cyborgs?}

\section{Natural-Born Cyborgs: Minds, Technologies, and the Future of Human Intelligence by Andy Clark \\ Oxford University Press: 2003. 229 pp. \$26 \\ Don Ihde}

Andy Clark illustrates his point that human intelligence is distributed globally far beyond the limits of the "ancient biological skin-bag" by referring to online bookseller amazon.com's practice of noting that people who bought books by this author also bought books by that one. So was it by coincidence, I wonder, that the very week that I was asked to review Natural-Born Cyborgs, Clark's name popped up under amazon.com's listing of my own book Bodies in Technology? Coincidence or not, I found Natural-Born Cyborgs to be simultaneously highly interesting, provocative and easy to read.

The term 'cyborg' is a portmanteau of 'cybernetic organism', coined by Manfred Clynes and Nathan Kline in 1960 and popularized by Donna Haraway in her essay Cyborg Manifesto. Here it is used to address the issue of human intelligence and embodiment, particularly with respect to the technologies that increasingly hybridize humans and machines. Clark, who heads the cognitive-science programme at Indiana University, is a second-generation cognitivist who has gone beyond the early logicism of artificial intelligence. He explores the notion that humans and their technologies have always been so closely interrelated that we have always been cyborgs. Now, however, by including technologies that are worn on the surface of our bodies or even implanted within them, we are beginning to open new dimensions for human intelligence. Clark's own perspective on these developments is dominantly optimistic, although he does include a list of worries in a chapter entitled "Bad borgs?".

I find Clark's position fascinating philosophically because he sometimes retains the cartesian 'consciousness-in-a-box' notion, which is now nearly 400 years old. Recently reinvented as a 'brain-in-a-vat' by Daniel Dennett, whom Clark often follows, this idea implies the existence of a homunculus - an all-controlling self - that is now simply relocated into a brain. Much cognitive science and some neurology support this highly localized notion of consciousness, the origins of which lie in René Descartes' use of the camera obscura as the model for the body and mind. But Clark also uses what I would call a phenomenological set of descriptions,

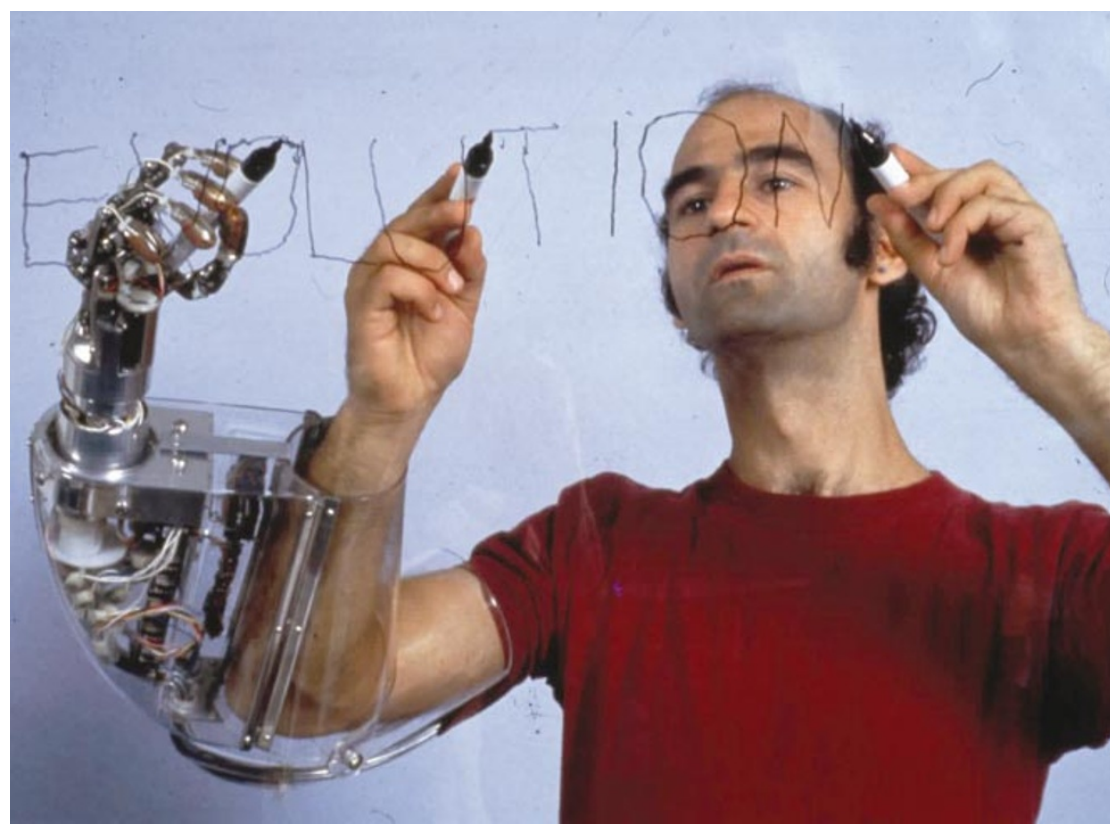

Many hands make light work for performance artist Stelarc, as he demonstrates his third arm.

in which our bodily self-experience goes well beyond the 'biological skin-bag' - a theme that Clark seems to get from the philosophers Hubert Dreyfus and Maurice Merleau-Ponty. Clark imaginatively, but sometimes inconsistently, combines these two drastically different ideas.

Clark recognizes that our bodily experience extends beyond the limits of the 'skin-bag' by means of tactility at a distance, through, as Merleau-Ponty suggested, the blind man's cane and the sense of bodily extension felt when driving a car. But the newer interfaces, both implants and wearable devices (particularly electronic ones), vastly extend these possibilities. Historically, many technologies were first designed as prosthetic devices, such as telephones for helping those with hearing difficulties, or typewriters for the visually impaired. New prostheses include artificial vision devices such as the 'Dobelle eye' and the 'tactile visual sensory substitution' system.

The book discusses both implant technologies, which are often still primitive, and experience-enhancing 'wearable' technologies. For example, the performance artist Stelarc wears a third hand that he can use for writing and gesturing. The array of such technologies discussed in Natural-Born Cyborgs is impressive and entertaining, giving the book a potentially wide audience that includes those interested in cognitive science, performance art and the philosophy of mind.

Clark's wide-ranging interests and knowl- edge of cutting-edge technologies also help him to overcome some of the traps (and hype) into which older artificial-intelligence, virtual-reality and techno-utopian fantasists often fall. Technologies as diverse as prosthetic cochlear implants and the Internet (discussed extensively in the chapters entitled "Where are we?" and "Global swarming") are shown as enhancements and extensions of human experience and intelligence. This is not to say that all implants provide such utilitarian enhancement. For example, Clark mentions a medical implant that triggers orgasms, and the information society, which brings many benefits, also causes problems through its increasing ability to keep tabs on us.

When reading Natural-Born Cyborgs there were moments when my tendency to criticize was piqued - for example, when Clark maintains a homunculus version of conscious brain activity, complete with a desire to control things centrally by giving commands, thus falling again into cartesian antiquity. Yet, by then recognizing that learning raises such technologies to skill levels not hindered by discrete commands, and by his emphasis on plasticity, Clark leads us to a sense of embodiment beyond the antique.

In the end, I was quite happy with the amazon.com dissolution of my degrees of separation from Andy Clark. Don Ihde is in the Department of Philosophy, Stony Brook University, Stony Brook,

New York 11794-3750, USA. 